\title{
Richardson Cross Lecture 1989 Amblyopia-An Historical Perspective
}

\author{
PETER FELLS
}

London

\begin{abstract}
Introduction
I am most honoured to have been asked to deliver the Richardson Cross lecture at this Symposium to celebrate the centenary of the first house surgeon at Bristol Eye Hospital.

After medical training at King's College Hospital Francis Richardson Cross enjoyed travel and study abroad in Europe beforè becoming a lecturer in anatomy at the Bristol medical school in 1878 and assistant surgeon to the Bristol Royal Infirmary. He was appointed surgeon to the BRI in 1879, and surgeon to the Bristol Eye Hospital in 1882. His first house surgeon was Hermann Snellen, son of his former teacher, Professor Snellen, at Utrecht who is remembered in Snellen's acuity test charts. A less well known fact was his period as resident medical officer at St. Pancras Infirmary where I served my own pre-registration year when that hospital had been taken over by University College Hospital. He also worked as clinical assistant at the Royal London Ophthalmic Hospital which later became Moorfields Eye Hospital, City Road branch. Our third hospital of common endeavour was, of course, Bristol Eye Hospital, the 1935 building for which he was largely responsible, and where I did my first ever training in ophthalmology from 1961-3. However, it may be that there the similarities end because it states in one of his obituaries that 'he was a fine speaker and was everywhere an influence for good'.
\end{abstract}

In this lecture I shall give a brief historical survey of early ideas on the nature of amblyopia and its association with strabismus. Different methods of treatment, àdvancing neurophysiological studies and changing ideas on the nature of amblyopia will be discussed. Many of the workers from 1965 onwards I know personally and it has always been a pleasure to meet and hear of their latest results and theories. Finally some questions must be asked. Can amblyopia be prevented? Is there an optimal therapy for amblyopia? Are there risks involved in treatment? And even, does amblyopia need treatment?

\section{Definition}

Dullness of vision, amblyopia, is defined by
Burian $^{1}$ as a unilateral or bilateral decrease of vision for which no obvious cause can be detected by physical examination of the eye and which in appropriate circumstances is correctable by therapeutic measures. However, von Graefe put it rather more succinctly: amblyopia is the condition in which the observer sees nothing and the patient very little. It affects 2 to $2.5 \%$ of the general population, and presents a huge problem with regard to diagnosis and therapy.

In the 19th century some workers considered amblyopia as congenital and the cause of any associated strabismus. Others, such as Donders (1864) blamed habitual suppression for the loss of vision. Priestley-Smith (1898) considered 'that these highly amblyopic eyes 
squint earlier than others just because they are amblyopic, but I think we ought not to leave out of consideration the possibility that the early onset of squint may arrest the visual development of the eye. The question is important in relation to educative treatment'. Maddox ${ }^{2}$ claimed that 'it is not for want of use that vision suffers but through seeing too much. The eye becomes a nuisance and the brain blinds it'.

\section{Occlusion}

As long ago as 1722 Saint Yves described occlusion of the dominant eye to promote use of the squinting eye. Buffon in 1743 recommended occlusion of the good eye to straighten the squinting one. Erasmus Darwin, ${ }^{3}$ grandfather of Charles Darwin, gave a much more comprehensive account of treating strabismus: 'If the squinting has not been confirmed by long habit, and one eye be not much worse than the other, a piece of gauze stretched on a circle of whale-bone, to cover the best eye in such a manner as to reduce the distinctness of vision of this eye to a similar degree of imperfection with the other, should be worn some hours every day. Or the better eye should be totally darkened by a tin cup covered with black silk for some hours daily, by which means the better eye will be gradually weakened by the want of use, and the worse eye will be gradually strengthened by using it. Covering an inflamed eye in children for weeks together, is very liable to produce squinting, for the same reason'.

Javal in France and Worth ${ }^{4}$ in England in the late 19th century were powerful advocates of correcting refractive errors and using occlusion for amblyopia. Worth had shown that the age at which a squint developed and the age at which treatment began were important in establishing the prognosis for recovery of vision. Worth recorded the age of onset of squint, the length of time the squint had been present before occlusion started, and the visual acuity finally reached in the deviating eye. From these results developed Worth's fraction-age in months when permanent turn became apparent/age in months at which training began, which was used prognostically. In passing I must mention that Ernest Maddox found the use of Worth's amblyo- scope in squint training so time-consuming that he taught his daughter, Mary, who worked as his secretary/receptionist, to use the amblyoscope.

\section{Orthoptics}

In 1929 Miss Maddox opened the first orthoptic clinic at the Royal Westminster Ophthalmic Hospital, more recently known as Moorfields Eye Hospital, High Holborn branch. In 1932 Miss Sheila Mayou opened an orthoptic clinic at the Central London Ophthalmic Hospital which in 1948 became the Institute of Ophthalmology, Judd Street. The British Orthoptic Society was formed in 1937 with Miss Maddox as president and Miss Mayou as chairman. After World War II Miss Mayou and her staff transferred to City Road and Miss Mayou was still head of the orthoptic department at Moorfields, City Road, when I started there as a resident in 1963 . A report by Miss Mayou in 1934 on the first two years at the Central London Ophthalmic Hospital stated: 'Our method with amblyopias has almost invariably been to start treatment with constant and total occlusion, lessening the size and opacity of the occluder as the vision improves. We have not found intermittent occlusion satisfactory and it has not been possible so far to experiment with intensive stimulation of amblyopic maculae'.

\section{Pleoptics}

A number of workers had tried ways of actively stimulating the retina of the amblyopic eye to overcome suppression, but the problem of eccentric fixation with its very poor prognosis seemed almost insuperable. Bangerter $^{5}$ showed that an amblyopic eye could fixate with a non-foveolar area even though clinical observation suggested central fixation. Estimates of the incidence of eccentric fixation in strabismic amblyopia vary from $23 \%$ to $82 \%$, depending upon the diagnostic methods used. Bangerter introduced 'pleoptics', meaning 'full' or 'more' vision, where he attempted functional destruction of eccentric fixation by intense dazzling or blinding light. This was followed by elaborate methods of stimulation of the fovea using a range of specially designed instruments-pleoptophore, localisator, centrophore, corrector, mnemoscope etc. 
Cüppers ${ }^{6}$ after visiting Bangerter at St Gallen, developed his own system, avoiding the 'blinding' of the retina but using more positive ways of promoting 'straight ahead localisation' once the diagnosis of eccentric fixation had been established. He devised the visuscope for diagnosis and then used the euthyscope to create after-images, both positive and negative types, to restore true spatial value of the macula. The Co-ordinator, using the entoptic phenomenon of Haidinger's brushes to improve foveal function and visual acuity, was employed. Unfortunately these methods were very time-consuming and needed'high levels of co-operation found only in older children. Fears that routine occlusion of the preferred eye would reinforce eccentric fixation have not been realised. Inverse occlusion of the amblyopic eye to break down abnormal fixation has not proved of value except in so far as it accustomed the older child to wear a patch before conventional occlusion was started. Red filter therapy to reestablish foveal fixation by only allowing light of longer than $640 \mu \mathrm{m}$ nerve length to reach the retina and stimulate the cones with total occlusion of the preferred eye is rarely used nowadays. Various combinations of prisms with occlusion therapy have been used for amblyopia with eccentric fixation, with a 'reverse prism' i.e. base-in for esotropia, in front of the amblyopic eye.

\section{Penalisation}

Both Javal and Worth originally used atropine to fog the fixing eye and encourage near fixation by the amblyopic eye. Later Knapp added miotics to the amblyopic eye but the most successful technique of differential focussing is 'penalisation'. Pouliquen ${ }^{7}$ developed this method of treating moderate levels of amblyopia, $6 / 18$ to $6 / 24$, with central fixation, based on an idea of Pfandl's (1958). Von Noorden finds the term 'penalization' most confusing with its overtones of punishment but he has overlooked another meaning of the French word 'penalisation' which is 'hindrance' and clearly the intended meaning in this context. Penalisation of the preferred eye is by atropine and the refractive correction of this hypermetropic eye may be exact, overcorrected or undercorrected, to penalise at near, at distance, or totally.

\section{Hubel and Wiesel}

It was the work of Hubel and Wiesel ${ }^{8,9}$ in the early 1960s that laid the basis for new concepts with regard to developing vision in early life. They showed that a short period of monocular deprivation in the early weeks of life could greatly alter the balance of input from the two eyes to individual neurones in the kitten's striate cortex. In place of the majority of cortical neurones being excited through either eye the physiological input from one eye virtually disappears if that eye is deprived of vision. However, deprivation of both eyes does not lead to blindness but most cortical cells can still respond to visual stimuli and be driven by either eye. It was proposed that the developing optic. radiations from each geniculate nucleus competed for influence on the cortical neurones. Later work by Guillery ${ }^{10}$ on the control of growth of neurones in the lateral geniculate nucleus (LGN) led to the theory of 'binocular competition'. Hubel and Wiesel's work in kittens revealed a distinct sensitive or critical period during which the binocular input to the striate cortex could be modified. This period lasts approximately from three weeks to three months in the kitten.

Blakemore demonstrated the ultimate in sensitivity with a dark-reared kitten after exposure to either vertically or horizontally orientated stripes for one hour on the twentyeighth day after birth showing appropriate tuning of the cortical neurones. Later experiments showed that the kitten made amblyopic by uniocular deprivation could have the ocular dominance of cortical cells returned to favour the initially deprived eye by a subsequent period of reverse suturing, where the originally deprived eye has the lids opened and the other eye has the lids closed by suturing. This work on cats with their rather different levels of mature visual acuity compared with primates has led to experiments being performed on juvenile monkeys by several workers around the world including Hubel and Wiesel, von Noorden, and Blakemore.

\section{Parallel Processing and Retinal Blur}

Hubel and Wiesel's work was carried out before it became generally known that there are distinct types of cat retinal ganglion cells. The two of major interest in this context are 
the sustained or X cells and the transient or $Y$ cells. They appear to make up at least two separate channels in the visual nervous system. The centrally situated retinal $X$ cells transmit their information via tonic slow nerve fibres to similar X cells in the lateral geniculate nucleus to visual cortical cells which have high spatial frequency tuning. Such a pathway would be used for spatial discrimination (visual acuity). The transient or Y cells from the retinal periphery transmit via phasic fast fibres to similar transient cells in the LGN and cortex. The cortical transient cells respond to low spatial frequency and high temporal frequency, and this channel would be appropriate for temporal discrimination providing the basis for analysis of movement and initiation of visual fixation reflexes. In 1973 at the Third Cambridge Ophthalmological Symposium Ikeda and Wright $^{11}$ proposed that amblyopia was due to a loss of sustained $X$ cell function and that this was caused by inappropriate stimulation of the fovea by habitually blurred images during the critical period of development. Ikeda, working initially with Wright and later with Tremain, carried out experiments on kittens in which they produced squints surgically that could be totally uni- lateral in type or with alternating fixation They measured the retinal visual acuity and also the LGN visual acuity by single cell recording as well as looking at the cortical cells and their ocular dominance patterns. Similar experiments were carried out with cats that had both eyes atropinised or only one eye atropinised (Fig. 1). It was only in the unilateral left squint with no alternation of fixation and in the unilaterally atropinised left eye that amblyopia of the $\mathrm{X}$ cells resulted, together with a shift of cortical dominance towards the right eye, and fewer cortical cells being excited by the amblyopic left eye. Note however that in the bilaterally atropinised cat both eyes appear to be amblyopic but the cortical cells have maintained their binocularity. ${ }^{12}$ At this stage it is worth emphasising that clinicians and neurophysiologists often have different understanding of the same words. This has been very emphatically pointed out by Jampolsky ${ }^{13}$ where he made it quite clear that 'binocular' to a scientist means that a cell is capable of being driven by either eye. 'Binocular' to the clinician suggests that particular cells must be capable of simultaneous input from either eye with the implications of sensory fusion and stereopsis. It is evident that

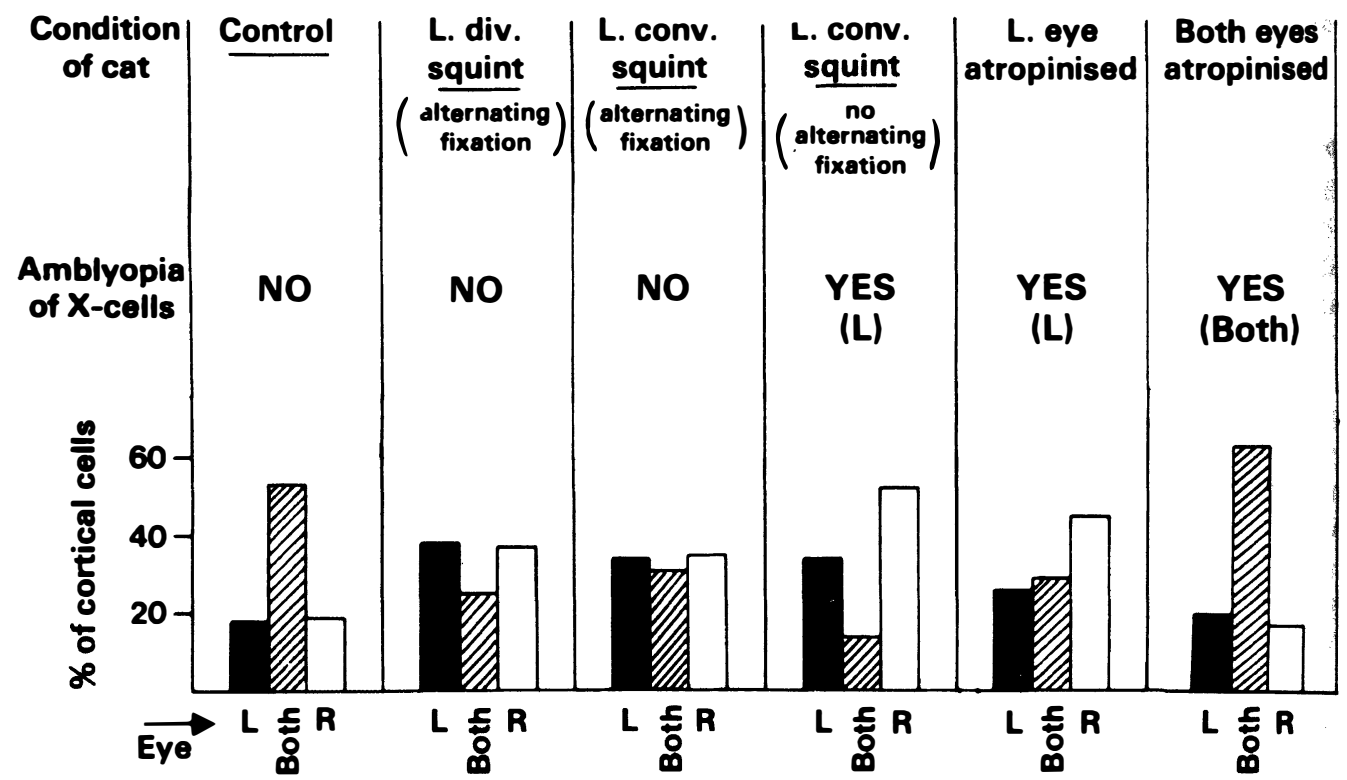

Fig. 1. The presence or absence of amblyopia of sustained $X$ cells in the retinal area centralis and the percentage of uniocularly and binocularly driven cells at the cortex in 6 different animal models, suggesting the independence of amblyopia and loss of binocularity (from IKEDA). 
Ikeda is using 'binocular' in the former sense. Ikeda claimed that the $\mathrm{X}$ cells in a strabismic deviation would receive blurred images and that both central retinal areas in bilateral high hypermetropia would receive blurred images. This inadequate stimulation would prevent the development of high quality cortical resolution. I must mention that in 1972 Hisako Ikeda came to see me at Moorfields to discuss the clinical implications of her research and she was most interested to learn in support of her hypothesis that a child with bilateral uncorrected high hypermetropia may accept blurred images in each eye, that is, bilateral amblyopia, without developing a squint or diplopia.

Some support for this peripheral origin for amblyopia has been given by Arden's work on pattern electroretinograms. ${ }^{14}$ There is a clear difference between the responses from the right and left eyes in this adult straight-eyed anisometrope, with only $6 / 24$ acuity in the left eye. In most amblyopes Arden found the response from the affected eye was $50 \%$ or less of the response from the fellow eye. In patients who had failed to respond to treatment of their amblyopia the asymmetry of response was highly significant. Later he confirmed that these pattern ERG changes occurred without reduction in foveal ERGs.

\section{Gratings and Contrast Sensitivity}

Although the measurement of visual acuity using patterns of alternating black and white bars, i.e. gratings, was first used over two hundred years ago (Mayer 1754) sinusoidal gratings have been used in the measurement of contrast sensitivity during the last two decades. The contrast sensitivity function of the eye determines the relationship between contrast sensitivity and spatial frequencies. ${ }^{15}$ The use of gratings has been an essential part of the neurophysiological studies on cortical cell responses to particular orientations of stimulation and they have also been used in establishing the 'oblique effect' whereby the acuity and resolution in central vision are better for horizontal and vertical orientations than for oblique ones. In the 1970 sess $^{16}$ amongst others began to use contrast sensitivity in studying different types of amblyopia: in strabismic amblyopia he showed there was a lower resolution limit in the amblyopic eye and also that there were two sub-groups in strabismic amblyopia. One group showed the abnormality only at high spatial frequencies and the other showed abnormalities at both high and low spatial frequencies. Two other features were noted by Hess. The contrast thresholds in strabismic amblyopes became normal when luminance levels were reduced while the deficit persisted in anisometropic amblyopia. Hess described another group of amblyopes who showed normal contrast thresholds for all spatial frequencies tested, and yet had severe local distortions within the pattern both at and above threshold. Other subjects with these supra-threshold changes had high and low frequency threshold abnormalities in addition to the supra-threshold distortions.

\section{CAM therapy}

It was in an attempt to improve acceptance by both patient and parent of occlusion therapy that Ruth Banks ${ }^{17}$ and Peter Watson at Cambridge tried occlusion of the preferred eye for only 20 minutes daily whilst intensive close work was being undertaken. This 'minimal occlusion therapy' appeared to be effective and together with Fergus Campbell at Cambridge they asked the question 'what would be the most effective stimulus for vision during this short period of occlusion?' With Campbell's knowledge of gratings and the cortical cells' orientational preferences it was decided to use a repetitive grating pattern with sharp luminance edges slowly rotating. After rotating through $180^{\circ}$ every orientational preference would have received some stimulation. The preliminary results were good both in terms of Snellen acuity and improvement in contrast sensitivity. Other groups of workers tried this method and confirmed that although visual acuity was not necessarily improved the method was effective in improving contrast sensitivity. CAM therapy, following its public announcement at the International Strabismological Association Congress in Kyoto in 1978, was tried widely in many countries, this time, however, properly controlled trials were used by Keith ${ }^{18}$ and Schor ${ }^{19}$ and others. Schor reviewed all 14 studies published after the preliminary report and before his own trial. 
Seven studies showed improvement in visual acuity or contrast sensitivity but had no controls, while of the five that did have controls four showed improvement in visual acuity for both the control and the treatment groups. Schor used a double masked trial and found that rotating gratings during short term occlusion had no significant effect on the visual acuity of the amblyopic eyes. It was found that CAM therapy could be used in children from four to five years of age but not normally younger than that and it was concluded that the gratings themselves do not improve the visual function of an amblyopic eye but that the effect could result from the minimal occlusion accompanied by the performing of a close visual task. Other workers such as Lennerstrand and Singer have suggested that arousal and attention mechanisms may also be involved in getting results with CAM therapy. Watson and Sanac ${ }^{20}$ in 1985 compared three methods of amblyopia therapy; namely conventional occlusion, minimal occlusion and CAM treatment, in 399 children and found each of these methods to be equally effective as an initial therapy. If the patient did not respond to one method then usually further improvement could be obtained by changing to one of the other methods of treatment. They also commented that a quarter of their patients did not respond positively to any of the methods tried. The apparent correctness of CAM therapy in the light of neurophysiological knowledge at that time made it doubly disappointing that the treatment did not succeed in the way that had been expected of it. The extent of failure of amblyopia therapy has not always been fully appreciated or admitted and in our own retrospective survey of new amblyopic patients referred to Moorfields during 1986 gave similarly disappointing results. Using the criteria of unilateral amblyopia as being two lines difference in corrected acuity and bilateral amblyopia being $6 / 9$ corrected acuity or less in each eye, we found a satisfactory result in unilateral amblyopia in only 50 out of 90 patients. These patients were treated by occlusion, and occlusion with glasses where they were indicated. The occlusion used had been on the basis of one hour per day for each year of age of the child, together with encouragement to carry out near vision tasks for as much of the time as was possible during the patching.

At this stage it is as well to review the known clinical causes of amblyopia, both unilateral and bilateral, to establish the common denominators of these different clinical conditions. An indefatigable worker in both the clinical and the neurophysiological work is Gunter von Noorden. ${ }^{21}$ The causes of unilateral amblyopia are strabismic, anisometropic and visual deprivation. The causes of bilateral amblyopia are uncorrected bilateral high hypermetropia and bilateral cataracts of equal density. These different types of amblyopia have also been classified with regard to light or form deprivation or abnormal binocular interaction. Von Noorden in 1972 proposed two possible amblyogenic mechanisms which could be at work separately or together. The first mechanism is either a lack of adequate retinal stimulation during infancy causing visual deprivation with arrest of development at the stage at which the interference occurred, or disuse atrophy of afferent connections that were already present at birth. The second mechanism is based on the view that stimulation of corresponding retinal points with unequal images causes rivalry between the two eyes which is decided in favour of the fixating eye, the fellow eye eventually becoming amblyopic. The lack of adequate retinal stimulation is clearly evident in anisometropic amblyopia where McMullen $^{22}$ in 1939 observed that the more hypermetropic eye never receives a clear image because there is no stimulus to produce the extra accommodation required to form a clear image in the more hypermetropic eye (Fig. 2). In anisomyopia the more myopic eye is usually preferentially in focus for near except when the myopia is of very high degree. Bilateral hypermetropia, usually of 5 dioptres or more, also clearly comes into this inadequate stimulation category. The problem with anisometropic amblyopia is that there may be some associated strabismus albeit only at the microtropia level and this certainly confounds the issue. However, in the straight-eyed anisometropic amblyope, where sharp and blurred images of the same object are being perceived, I am not certain of the extent to which abnormal binocular input 


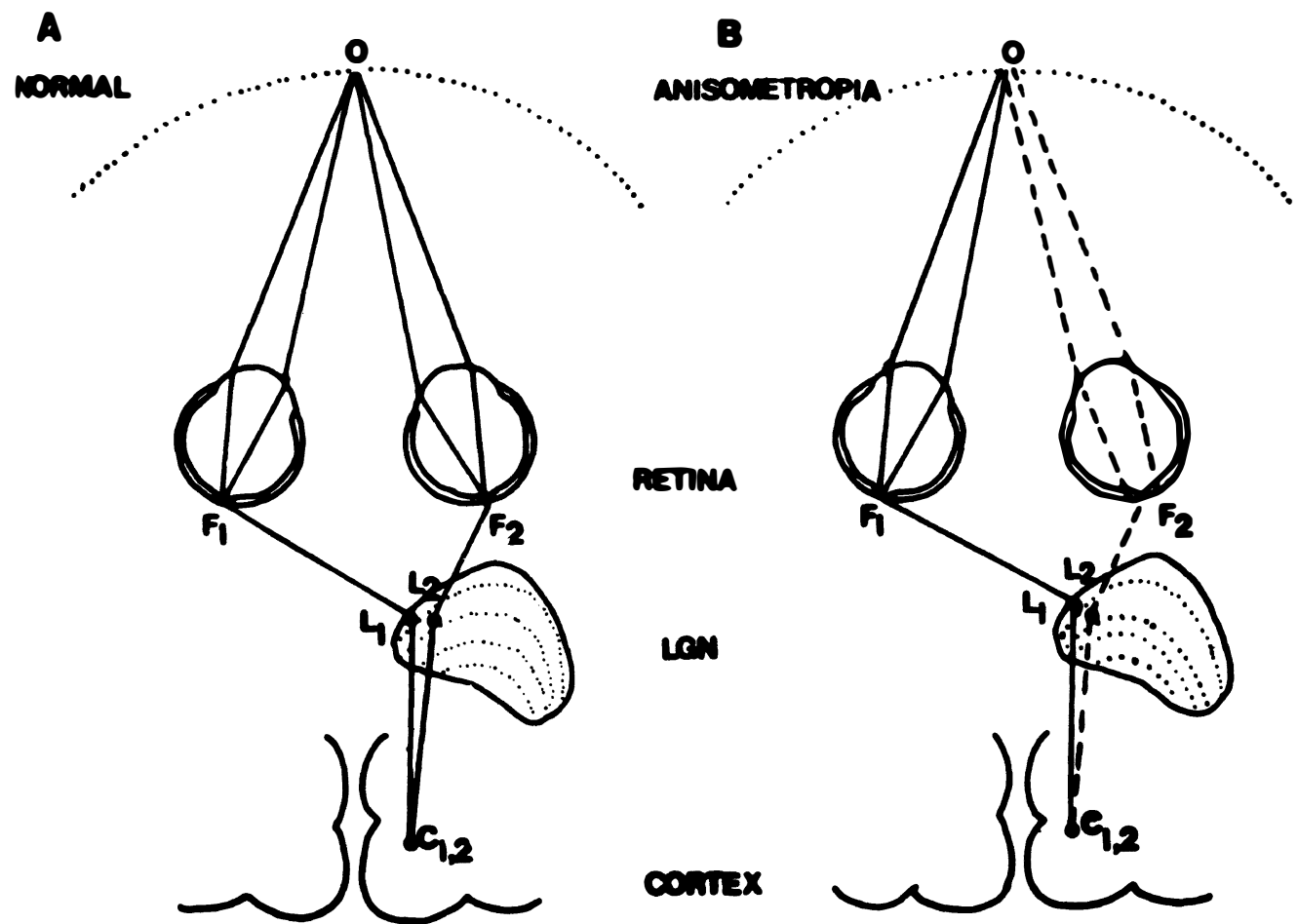

Fig. 2. Simplified diagrams of visual pathways in (a) the normal child and (b) where the right eye is hypermetropic producing a blurred foveal image. The left eye input dominates the visual cortical cells (from IKEDA).

has to be expected. Ikeda has proposed that in strabismic amblyopia the deviated eye always receives a blurred image, but it is apparent that there will be a number of visual objects that are equidistant from the object fixated by the dominant eye and thus imaged on the fovea of the deviating eye. The important feature here is that each eye receives incompatible visual stimulation (Fig. 3). Burian called strabismic amblyopia the amblyopia of misuse. The evidence of abnormal binocular interaction has been well established by the neurophysiologists and further evidence supporting this is being accumulated by psychophysical experiments.

\section{Accommodation}

It is widely recognised that the most intractable form of unilateral visual deprivation is that caused by a unilateral cataract. Even if very early surgical treatment in the first weeks of life in the human is undertaken, intensive treatment with contact lenses and occlusion therapy is rarely effective in producing signifi- cant improvement in visual acuity. Where patients who have suffered a traumatic unilateral cataract after the age of seven years, before which there had been no reason to expect anything but normal visual development, the treatment of such a cataract surgically and wearing of a contact lens that gives good acuity, is still followed by an over $50 \%$ rejection of continued contact lens wear by the end of the first year. Even trying a multifocus reading addition by way of spectacles over the contact lens gives no further benefit and both optical aids are abandoned. It would appear that the factor of accommodation and in particular its complete absence unilaterally, compared with the more hypermetropic eye in anisometropia always being underaccommodated, is a particularly significant prognostic factor. Patients with Duane's syndrome and Brown's syndrome even where there is significant strabismus rarely have severe or even moderate amblyopia. Could this be because of the normal accommodation enjoyed by these patients? All the effective 


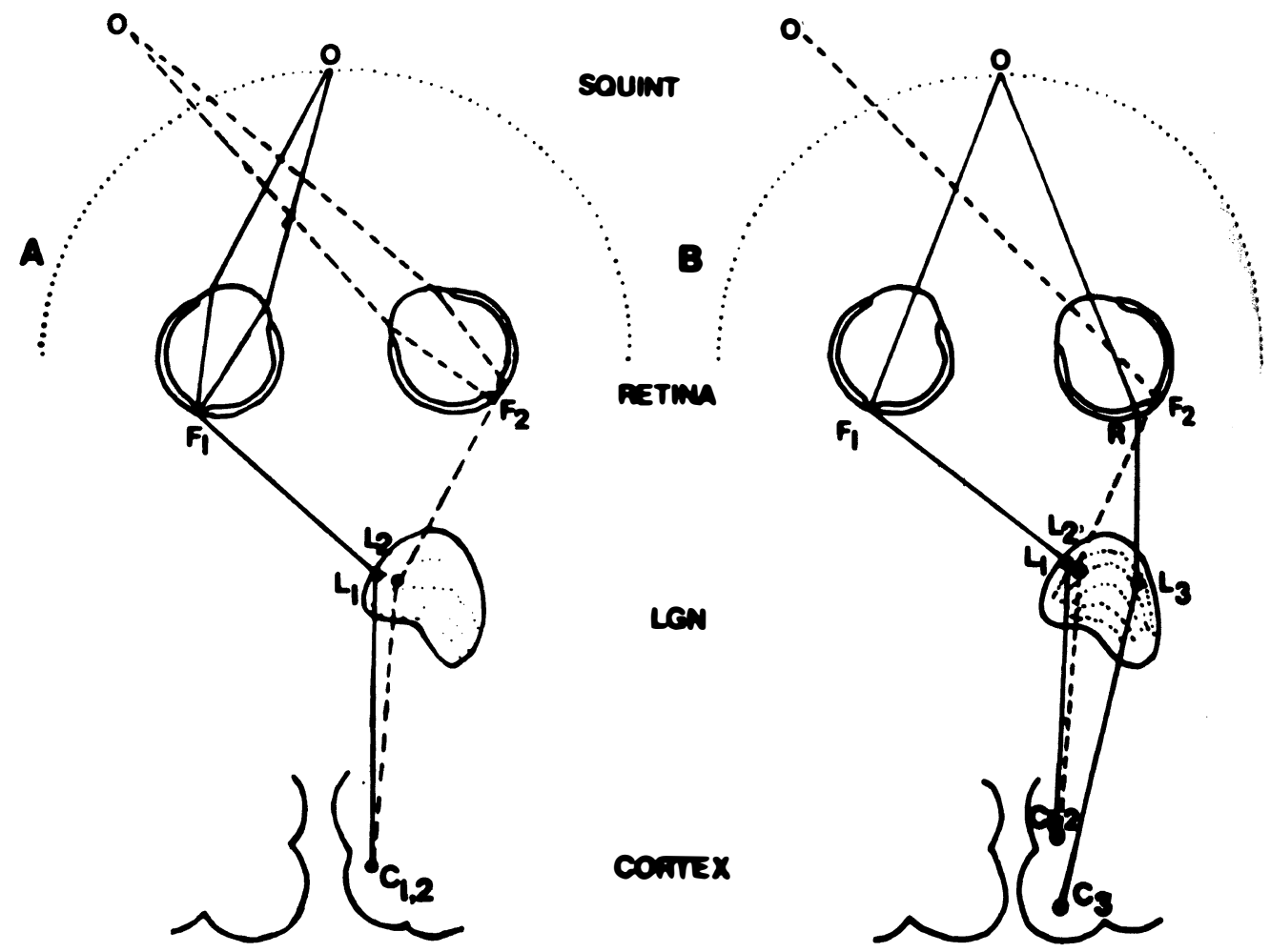

Fig. 3. (a) The esotropic eye has a blurred foveal image (b) The esotropic eye also has the nasal retina stimulated by the principal object of regard and visual cortical cells receive conflicting input (from IKEDA).

methods of treating amblyopia that have been developed over the past 70 years have included specific use of the amblyopic eye at near, thereby exercising its accommodation, with or without involving use of the hand in co-ordinated activities such as drawing and writing. It is also well known that to maintain the improved acuity after successful treatment of amblyopia it is often necessary for the patient to continue with periods of part-time occlusion of the preferred eye during reading until as late as eight and a half or even nine years of age. Penalisation therapy is effective because not only is the amblyopic eye given accurate refractive correction but the accommodation of the preferred eye is abolished, together with fogging at particular distances. For all of these reasons I would suggest that accommodation is an area that should receive further detailed attention in both our neurophysiological investigations of amblyopia and in its clinical improvement.

\section{Prevention}

Looking at amblyopia prevention: Atkinson and Braddick ${ }^{23}$ have been two of the workers most concerned with detecting refraction changes in infancy and have also looked at correcting such errors in early life. They used photofraction and retinoscopic refraction and assessed the results on acuity by preferential looking techniques. About $5 \%$ of the infant population studied showed hypermetropia of at least four dioptres in more than one axis. This hypermetropia becomes less with age and the rate of reduction depends upon the axis of any associated astigmatism. Early astigmatism disappears more readily if the more hypermetropic axis is horizontal. Untreated hypermetropia found in infancy is a good predictor of strabismus and reduced acuity in later pre-school years. The group of infant hypermetropes who wore spectacle correction showed a lower incidence of strabismus and poor acuity than did the untreated 
group who had the same refractions in infancy. The treated hypermetropic infants did not differ significantly from the control children. When the children were retested after four years of age many of the hypermetropes who did not pass the acuity test at four years did so by age five years: that is to say the effects of infant hypermetropia appeared to delay visual development rather than impair it permanently. The problems of spectacle wear in infants under 12 months of age are largely those of education and understanding by their parents of the objects of the exercise and hence the parents' motivation.

\section{The effects of occlusion}

Preferential looking has enabled infants of only a few months of age to have the development of their visual acuity assessed. ${ }^{24}$ Measurement of the visual acuity in an esotropic infant before, during and following occlusion of the fixing eye, showed that although there was the expected improvement in the acuity of the amblyopic eye this improvement was not always maintained in the ensuing weeks. Surprisingly the preferred eye showed a fall in acuity after occlusion and this was followed by an improvement to super-normal levels three weeks after the termination of occlusion. This has been called the trade-off effect. If it is possible to produce lasting results by very short-term occlusion of not more than 20 minutes per day then this would appear to be the preferred method because such occlusion will be much less disruptive of other processes within the visual cortex. Some workers prefer to use total occlusion and to alternate this between the eyes, perhaps in a ratio initially at three days on the preferred eye then one day on the amblyopic eye, before returning to the preferred eye with the occlusion and never leaving the two eyes open at the same time for possible competitive cortical stimulation. This will undoubtedly provide good stimulation of the visual cortical cells in turn and at the same time obviate the risk of abnormal binocular interaction. However, it is not known what this may be doing to the binocular potential of visual cortical cells and subsequently to the possibility of some form of binocular single vision developing in the child. Certainly this alternating occlusion reduces but does not completely prevent the risk of occlusion amblyopia developing in the initially preferred eye.

Experimental work on the sensitive period in the primate striate cortex has shown what was already demonstrated by Hubel and Wiesel's work that there are several sensitive periods depending upon which cells in which layer of the cortex are under consideration. There is a clear difference in the duration of the period of sensitivity to uniocular deprivation outside and within layer $4 \mathrm{C}$, and these differences are confirmed by reverse suturing in the juvenile monkey. Awaya, ${ }^{25}$ working on the sensitive period of the visual system in humans, has established that the sensitivity for deprivation amblyopia in humans is relatively low in the early weeks after birth and rises to a maximum around the eighteenth month of life and thereafter reduces fairly quickly to thirty months of life but the sensitive period continues until approximately eight years of age. He cautions against even short periods of occlusion before the age of thirty months. Awaya also draws attention to the comparison that Hubel had shown that the sensitive period in monkeys is about four times shorter than in humans; this also fits with Teller's finding that the development of acuity proceeds about four times faster in monkeys than in humans. Blakemore makes a number of interesting comments on the development of spatial resolution and the basis of amblyopia. There is no unequivocal reason why a modest decrease in the territory of innervation in layer $4 \mathrm{C}$ or even a gross shift in ocular dominance of cortical neurones should lead to a decrease of visual acuity through the eye in question. Behavioural determination of the way in which visual acuity develops in both human and monkey infants shows improvement by a factor of at least 30 times in visual acuity over a long period of time after birth. Determination of spatial resolution and contrast sensitivity of individual neurones in the LGN and striate monkey cortex shows a similar increase in spatial resolution which parallels the behavioural acuities. Much of the improvement in the spatial resolution of LGN cells before six months of age and all the subsequent increase 


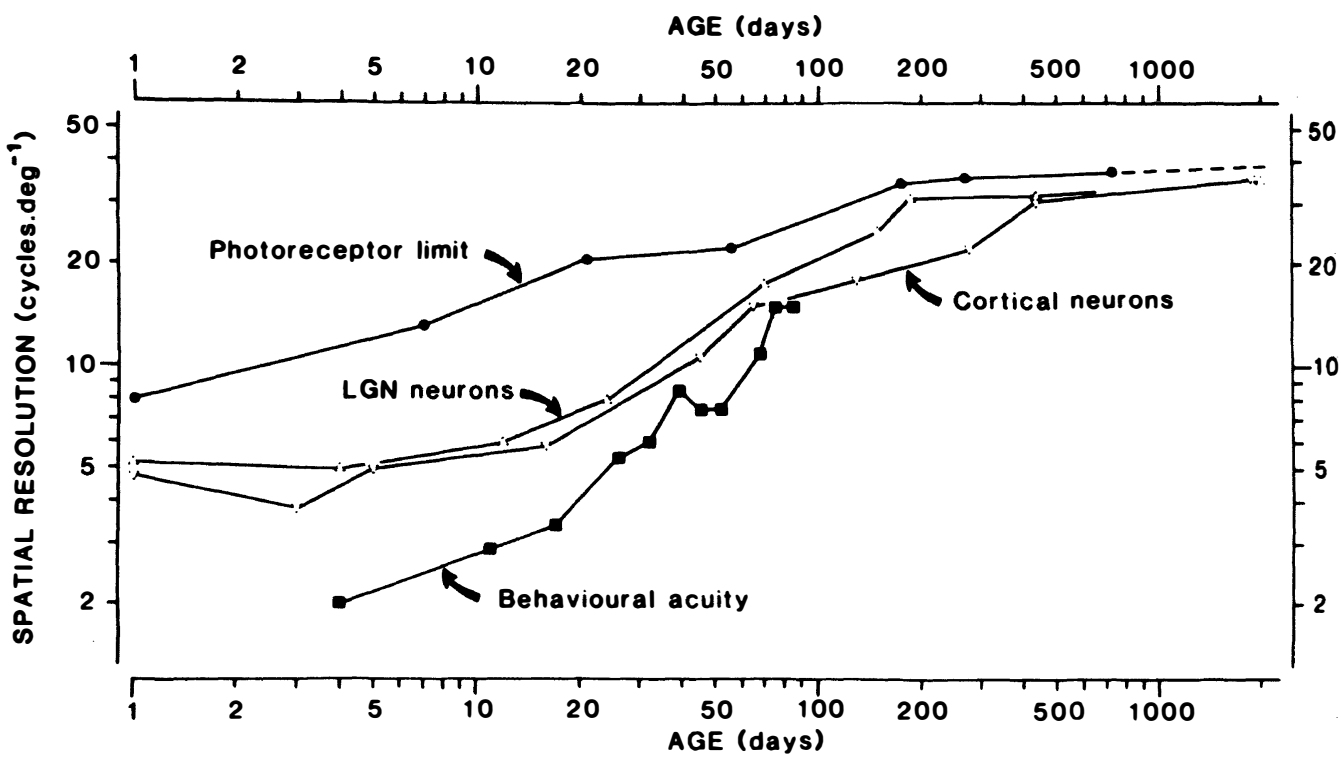

Fig. 4. These curves represent limits to the resolution of spatial detail in normal monkeys of different ages. In each case resolution (in cycles per deg. of visual angle) is plotted against age. The filled circles plot estimates of the absolute limit to resolution imposed by the foveal cone mosaic, based on Hendrickson and Kupfer's (1976) measurements of the diameter of the rod-free area in pigtail macaque monkeys, combined with Blackmore and Vital-Durand's (1986) measurements of the growth of the monkey eye and hence the increase in retinal magnification. The unfilled triangles (upright for the LGN; inverted for the striate cortex) show the maximum spatial frequency of a high-contrast drifting grating that produced a just-detectable response from the bestperforming neurons. (Data of Blakemore and Vital-Durand, 1983, 1986). Finally, the filled squares plot behavioural determinations of visual acuity, based on the preferential looking technique, for a single pigtail macaque (F2) from the study of Teller et al. (1978). (Unpublished analysis of D.S. Jacobs and C. Blakemore).

is probably accounted for by passive changes in the linear packing of foveal cones and growth of the eye. Even very prolonged monocular deprivation from birth, which certainly causes severe amblyopia in monkeys, seems to cause little if any retardation in the development of spatial properties at the level of the LGN. This means that severe amblyopia cannot be due to a simple retardation of the normal developmental improvement of acuity. Thus we have deprivation of form vision with little if any effect on the development of geniculate neurones and yet it grossly interferes with the maturation of spatial properties at the level of the striate cortex producing cells there with spatial resolution and contrast sensitivity similar to or even worse than those found at birth. (Fig. 4).

\section{Conclusions}

The neurophysiological studies have produced much information concerning the way in which the visual cortex develops initially along innate, predetermined lines, which allow for fine tuning by visual experience in very early life. A whole family of sensitive periods has now been established for different cells and different functions and it is not yet clear exactly how these compare with the sensitive period during which therapy may be used in the amblyopic human infant. Recent research shows that excitatory amino acid receptors are involved in the retinal output reaching the dorsal lateral geniculate nucleus relay cells. Furthermore, there is a corticofugal projection to the dorsal LGN from layer six of the visual cortex and this provides a synaptic input which in magnitude exceeds that from the retina. The cortex itself therefore exerts powerful control over the information that it accepts from the eye. ${ }^{27}$

At the much simpler pragmatic clinical level we have travelled full circle from occlusion therapy to straighten the squinting eye and improve its function through to elaborate methods of active stimulation of the macula to 
re-establish its activity and restore acuity to the brilliant concept of the CAM stimulator and finally back again to occlusion therapy than which there appears to be nothing better so far. Debate still continues as to whether the occlusion should be whole-time alternating between the eyes, or minimal occlusion, to produce the desired result. In recent years there has been no doubt in my mind that minimal occlusion can work well if it is carefully monitored but in the cases where it does not appear to be working there are now many orthoptists and ophthalmologists who are not prepared to go on to longer periods of occlusion. In my own Department looking at the patients who fail to respond to apparently properly carried out occlusion therapy, we have found that admission to the Children's Ward, where we have a full-time play therapist who is also a counsellor, has led to occlusion, and spectacles where indicated, being worn properly and with the mother and child both understanding what is required. Three to five days of in-patient treatment have enabled the occlusion therapy to continue on a satisfactory basis outside the hospital. What was most interesting about this study was that in 18 out of 19 cases there was evidence of severe social and psychological disruption within the family so that exhortation to establish and supervise occlusion therapy was the last straw and the mother was no longer able to cope. The factors ranged from impending to actual divorce, or in one case the father being away in prison.

Why do we spend so much time trying to treat amblyopia when the patient has a sound eye in addition to the amblyopic one? Is all the time and expense and frustration worth the end result? There is remarkably little published about the effects of amblyopia on effective functioning of the human visual system and in particular in relation to such complex activities as driving a vehicle. It is, however, known that someone with an amblyopic eye is more liable to damage or injure the preferred eye and then have to manage with the amblyopic eye as his only functioning, seeing organ. Under these circumstances when the competition between the two eyes has been irrevocably changed in favour of the amblyopic one, there is sometimes a small but worthwhile increase in the acuity of the formerly amblyopic eye. This may be helped by use in the adult of such therapies as pleoptics or CAM stimulation, however, the figures here are all very small. A much more common problem is that of knowing what to say to the parents who bring along a child at nine years of age or more who has an amblyopic eye that has failed to respond to all forms of treatment that have been tried. At this stage I tell the parents that the amblyopic eye sees light and colours and most importantly detects peripheral movement as readily as the preferred eye and the movement in the temporal field excites a fixation reflex bringing the object under the detailed scrutiny of the unaffected eye. This simple reassurance often gives much comfort, particularly when many parents have been given to understand that the amblyopic eye is a "blind" eye.

The mechanisms of amblyopia are yielding slowly to scientific investigations. Whether the answer lies in a better understanding of inhibition and suppression processes within the brain, or of the rôle of accommodation in aetiology and treatment of amblyopia only time will tell.

\section{Acknowledgements}

Figure 1 is reproduced by permission of the Journal of the Royal Society of Medicine.

Figures 1,2 and 3 are reproduced by permission of Dr Hisako Ikeda.

Figure 4 is reproduced with acknowledgement to the book Strabismus and Amblyopia edited by Lennerstrand, von Noorden and Campos, and published by Macmillan in 1988, together with permission from Professor Colin Blakemore.

\section{References}

${ }^{1}$ Burian HM and von Noorden GK: Binocular vision and ocular motility. 2nd ed. Mosby 1980, 219-20.

${ }^{2}$ Maddox EE: Tests and studies of ocular muscles. Quoted by Revell, MJ in his Strabismus. Barrie and Jenkins, London, 1971; 164.

${ }^{3}$ Darwin E: Zoonomia. vol III: 1801 ; 236-7.

${ }^{4}$ Worth C: Squint. 1st ed. London 1903; 76.

${ }^{5}$ Bangerter Amblyopiebehandlung. Bibliotheca Ophthalmologica Supplement 37: Karger, Basel, 1953: 62-3.

${ }^{6}$ Cüppers C: Moderne Schielbehandlung. Klin Monatsbl Augenheilkd 1956; 129: 579-604.

${ }^{7}$ Pouliquen M-P: Zum Problem-der Penalisation. Klin Monatsbl Augenheilkd 1972, 161: 130-9.

${ }^{8}$ Hubel DH and Wiesel TN: The period of susceptibility to the physiological effects of unilateral eye 
closure in kittens. J Physiol (Lond) 1970, 206: 419-36.

${ }^{9}$ Wiesel TN: Postnatal development of the visual cortex and the influence of environment. Nature 1982, 299: 583-91.

${ }^{10}$ Guillery RW: Binocular competition in the control of geniculate cell growth. J Comp Neurol 1972, 144: $117-30$.

${ }^{11}$ Ikeda $\mathrm{H}$ and Wright $\mathrm{MJ}$ : Is amblyopia due to inappropriate stimulation of the 'sustained' pathway during development? Br J Ophthalmol 1974, 58: $165-75$.

${ }^{12}$ Ikeda H: Visual acuity, its development and amblyopia. J Roy Soc Med 1980, 73: 546-55.

${ }^{13}$ Jampolsky A: Unequal visual inputs and strabismus management: a comparison of human and animal strabismus. In Symposium on Strabismus: Trans New Orleans Academy of Ophthalmology, St Louis. CV Mosby, 1978; 378-492.

${ }^{14}$ Vaegan, Arden GB and Fells P: Amblyopia: some possible relations between experimental models and clinical experience. In Wybar KC, Taylor D eds. Paediatric Ophthalmology, New York: Marcel Dekker 1983; 291-312.

${ }^{15}$ Campbell FW and Robson JG: Application of Fourier analysis to the visibility of gratings. $J$ Physiol (Lond) 1968, 197: 551-66.

${ }^{16}$ Hess RF: On the assessment of contrast threshold functions for anomalous vision. Br Orthoptic $J$ 1974; 41: 1-14.

${ }^{17}$ Campbell FW, Hess RF, Watson PG, Banks R. Preliminary results of a physiologically based treatment of amblyopia. Br J Ophthalmol 1978, 62: $748-55$.

${ }^{18}$ Keith CG, Howell ER, Mitchell DE, Smith S. Clini- cal trial of the use of rotating grating patterns in the treatment of amblyopia. $\mathrm{Br} \mathrm{J}$ Ophthalmol 1980, 64: 597-606.

${ }^{19}$ Schor C, Gibson J, Hsu M, Mah M. The use of rotating grating patterns for the treatment of amblyopia: a clinical trial. Am J Optom Physiol Opt 1981, 58: $930-8$.

${ }^{20}$ Watson PG, Sanac AS, Pickering MS. A comparison of various methods of treatment of amblyopia. Trans Ophthalmol Soc UK 1985, 104: 319-28.

${ }^{21}$ von Noorden GK: Amblyopia: a multidisciplinary approach. Invest Ophthalmol Vis Science 1985, 26: 1704-16.

${ }^{22}$ McMullen WH. Some points in anisometropia. Trans Ophthamol Soc UK 1939, 59: 119-24.

${ }^{23}$ Atkinson J: New tests of vision: screening and assessment in infants and young children. In French JH, Harel S and Caesar P eds. Child Neurology and Developmental Disabilities. Paul H. Brookes Publishing Co. 1989; 219-227.

${ }^{24}$ Held R: Normal visual development and its deviations. In Lennerstrand G, von Noorden GK, Campos EC eds. Strabismus and Amblyopia, London: Macmillan 1988. Chapter 20, 247-257.

${ }^{25}$ Awaya S, Miyake S, Koizumi E, Kamiya A, Hirai T: The sensitive period of visual system in humans. In Lenk-Schafer M, Calcutt C, Doyle M, Moore S eds. Orthoptic Horizons, Trans 6th International Orthoptic Congress, 1987; 44-48.

${ }^{26}$ Blakemore C. The sensitive periods of the monkey's visual cortex. In Lennerstrand G., von Noorden GK, Campos, EC eds. Strabismus and Amblyopia, 1988; 219.

${ }^{27}$ Sillito AM and Murphy PC. The modulation of the retinal relay to the cortex in the dorsal lateral geniculate nucleus. Eye 1988' 2 (Suppl) 221.

\section{ERRATUM}

Eye Volume 4 No. 5 Page 771-772

\section{Book Reviews}

\section{Basic Refraction Techniques by David Michaels}

The last sentence of this review should read: "I cannot recommend this book to our junior staff as a text book for examination preparation. However, it provides a useful stepping stone as a practical manual for those learning how to perform the clinical refraction of a patient." 